\title{
The translation of knowledge as a subsidy for the nursing practice
}

\section{Maria de Fatima Fernandes Vattimo ${ }^{1}$ \\ ORCID: 0000-0002-7036-5676 \\ Cassiane Dezoti da Fonseca" \\ ORCID: 0000-0002-2118-8562

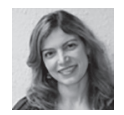 \\ 'Universidade de São Paulo. São Paulo, Brasil "Universidade Federal de São Paulo. São Paulo, Brasil \\ How to cite this article: Vattimo MFF, da Fonseca CD. The translation of knowledge as a subsidy for the nursing practice. Rev Bras Enferm. 2019;72(3):582-3.} doi: http://dx.doi.org/10.1590/0034-7167.2019720301
Discoveries and innovations in the Biomedical and Biotechnology areas changed the clinical research reality. Progress in Molecular Biology, Genomic Sciences, Cell and Tissue Engineering, Proteomics Technologies, Bioengineering, Bioimaging and Computational Methods are among the many advances that contribute to health promotion ${ }^{(1)}$. Basic research, preclinical research, clinical research, systematic reviews, phenomenological studies or social representations seek to respond to a singular goal: to elucidate the demands of the care practice. However, there is still a gap between research evidence and its application to individual or community care.

Translational research aims to accelerate the applicability of the findings generated in laboratory research and preclinical studies to the development of clinical trials and studies in humans. The National Cancer Institute of the United States was considered one of the pioneering institutions in the operationalization of translational research, with the creation, in 2005, of The Translational Research Working Group (TRWG). The University of Washington then created the Institute of Translational Health Sciences (ITHS) to strengthen Genetic Medicine(2). In Brazil, the National Council for Scientific and Technological Development (CNPq) created the National Institute of Translational Science and Technology in Medicine (Instituto Nacional de Ciência e Tecnologia Translacional em Medicina - INCT-TM), in 2008. Its objective was improving the conditions so that the production of bench results (pre-clinical) was transferred to the clinical context, creating patents and innovative products.

"Bench to bedside" is an expression that characterizes translational research and sustains its three main pillars: the bench, the bedside and the community ${ }^{(3)}$. Translational research involves four stages: $\mathrm{T} 1$ (from discovery to health care application); T2 (from clinical application to evidence-based guidelines); T3 (from evidence-based guidelines to their dissemination in medical practice); T4 (from medical practice to health impacts). These stages are bidirectional and feedback themselves with the objective of consolidating the proposed scientific idea (drug, therapy, instrument, etc.). (2) $^{\text {. }}$

In this context, the multiprofessional health team plays a fundamental role in the construction, development and execution of these stages, considering that many of these professionals (nurses, physicians, physiotherapists) act by the "bedside" and in the "community".

In this sense, by observing human responses to pathologies, Nursing actively participates in the stages of translational research towards directing the clinic to benchwork. In addition, Nursing, in its configuration in the $21^{\text {st }}$ century, is a protagonist in the production of knowledge in the Health area, highlighting its performance in the basic areas of Scientific Research, signalling the existence of new paradigms for its formation and qualification.

Thus, nursing scientists are characterized as true entrepreneurs of translational health research, because they corroborate the development of studies in both the pre-clinical and clinical spheres. 


\section{REFERENCES}

1. Fontanarosa PB, Bauchner H. Scientific discovery and the future of medicine. JAMA. 2015;313(2):145-6. doi: 10.1001/jama.2014.17937.

2. Guimarães R. Pesquisa translacional: uma interpretação. Ciênc Saude Colet [Internet]. 2013; [cited 2019 Mar 24]18(6):1731-44. Available from: http://www.scielo.br/pdf/csc/v18n6/24.pdf

3. Cohrs RJ, Martin T, Ghahramani P, Bidaut L, Higgins PJ, Shahzad A. "Translational Medicine definition by the European Society for Translational Medicine". New Horiz Transl Med.2015;2 (3): 86-88. doi: 10.1016/j.nhtm.2014.12.002 